\title{
Nonlinear finite element and fiber element analysis of concrete filled square steel tubular (cfst) under static loading
}

\author{
Mahmud Kori Effendi ${ }^{1, *}$ Nor Hayati Abdul Hamid ${ }^{2}$ \\ ${ }^{1}$ Civil Engineering Departement, Faculty of Engineering, Universitas Negeri Semarang (UNNES), Indonesia \\ ${ }^{2}$ Institute for Infrastructure Engineering, Sustainability and Management (IIESM), Universiti Teknologi MARA, 40450 Shah Alam, \\ Selangor, Malaysia
}

\begin{abstract}
The combination of thin-walled steel structure with concrete infill can be used as the alternative material properties in the building in Indonesia. This composite material is suitable for seismicresistant building because it has more ductility than conventional material. In the tsunami event, some tsunami debris strikes the building and induced partial or full collapse of the building. The loading tip shape of tsunami debris which contacts to a tubular surface affects the local deformation or buckling mode of the thin-walled structures. In order to investigate the effects, we conducted three-dimensional nonlinear finite element analyses of concrete filled square steel tubular members subjected to concentrated lateral loads by using the finite element analysis (FEM) program MSC Marc/Mentat. The fiber element analysis is also performed to reduce the analysis time of FEM and simplify the analysis. The accuracy of the FEM and fiber element analysis is verified by the experiment. Being based on the parametric numerical study, it discusses the effect of axial load on the load-deflection relations. It shows that the higher the axial load, the more degradation the ductility of the structure.
\end{abstract}

\section{Introduction}

The combination of steel tube structure filled with concrete can be used as the alternative material properties in the building in Indonesia. This composite material is suitable for seismic-resistant building because it has more ductility than conventional material [1-4].

The flexural behavior of Concrete Filled Square Steel Tubular (CFST) beams has been investigated by several researchers [5-7]. The concrete infill improves the ductility and flexural strength of structural members of CFST beam as well as preventing local buckling of steel tubes [8].

The study of the behaviour of CFST beams under pure bending by finite element analysis (FEA) has been performed by many researchers. Elchalakani et al [9] conducted FEA of steel tube beams with circular section (CHS) with concrete infill subjected to a static plastic pure bending. The concrete is modelled with damaged plasticity model with softening effect and Von-Mises yield criterion with hardening effect was used for steel. Three-dimensional FEA models of CFST have been used by many researchers, by using ANSYS software [10 12] and by ABAQUS software [13 - 14].

In the tsunami event, some tsunami debris strikes the building and induces partial or full collapse of the building. The loading tip shape of tsunami debris which contacts to a tubular surface affects the local deformation or buckling mode of the thin-walled structures. In order to investigate the effects, three-dimensional nonlinear
FEA of CFST square members subjected to concentrated lateral loads were conducted by using the FEA program MSC Marc [15]. The nonlinear material and nonlinear geometry have taken into consideration in the FEA.

The FEA running program takes too much time to converge. To solve this problem, we conducted numerical model based on fiber element discretization written by Kawano [16]. This analysis can predict effectively the response of concrete-filled steel tubes for pseudo-static and seismic loading [17]. The result of the FEA and fiber element analysis are then verified against the experimental results by Effendi [18]. The parametric study of the effect of the axial load is studied by means of fiber element model.

\section{Experimental Program}

In order to verify the proposed model, one specimen in total had been tested. Table 1 shows the detail of specimens in the experimental study.

\subsection{Material Properties}

The square section of the specimen, the specimen length and the loading position is shown in Fig. 1. The yield stress and the Poisson's ratio were $366 \mathrm{~N} / \mathrm{mm}^{2}$ and 0,3 , respectively. Table 1 shows the dimension and the material properties of the specimen. The name of the specimen is Sfs with a ratio of width and thickness

\footnotetext{
${ }^{*}$ Corresponding author: mahmud.kori@mail.unnes.ac.id
} 
$(B / t=33,2)$. The specimen had been tested at the Department of Architecture, Kyushu University [18].

\subsection{Experimental Set-up}

The test specimen was tested using one point load at the mid-span of the specimen as shown in Fig. 2. The pin and roller supports are installed at both ends. The load is under displacement control with $500 \mathrm{kN}$ capacity hydraulic actuator at a rate of $0.3 \mathrm{~mm} / \mathrm{min}$.

The overall square beam displacement is measured by the laser displacement sensor installed at bottom of the mid-span beam. Strain gauges were installed at quarter span and at bottom of mid square beam. The displacement of loading head is monitored with the two displacement transducers.

Table 1. Setting Word's margins.

\begin{tabular}{|c|c|c|c|c|c|}
\hline \multicolumn{4}{|c|}{ Steel Tube } & \multicolumn{2}{|c|}{ Concrete } \\
\hline $\begin{array}{c}{ }_{s B} B \\
(\mathrm{~mm} \\
)\end{array}$ & $\begin{array}{c}t \\
(\mathrm{~mm} \\
)\end{array}$ & $\begin{array}{c}f_{y}\left(\mathrm{~N} / \mathrm{mm}^{2}\right. \\
)\end{array}$ & $\begin{array}{c}E_{S} \\
\left(\mathrm{~N} / \mathrm{mm}^{2}\right. \\
)\end{array}$ & $\begin{array}{c}{ }_{C} \sigma_{B} \\
\left(\mathrm{~N} / \mathrm{mm}^{2}\right. \\
)\end{array}$ & $\begin{array}{c}E_{c} \\
\left(\mathrm{~N} / \mathrm{mm}^{2}\right. \\
)\end{array}$ \\
\hline $\begin{array}{c}100 . \\
0\end{array}$ & 3.0 & 366 & 189000 & 71.5 & 39760 \\
\hline
\end{tabular}
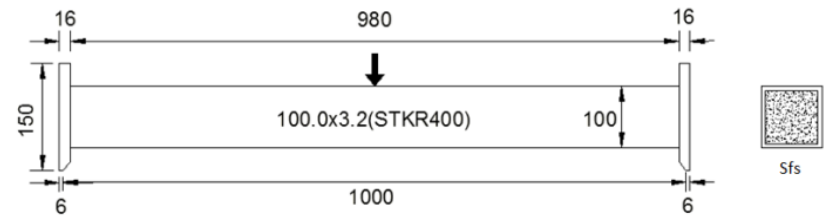

Fig. 1.Specimen's Illustration (unit: $\mathrm{mm}$ )

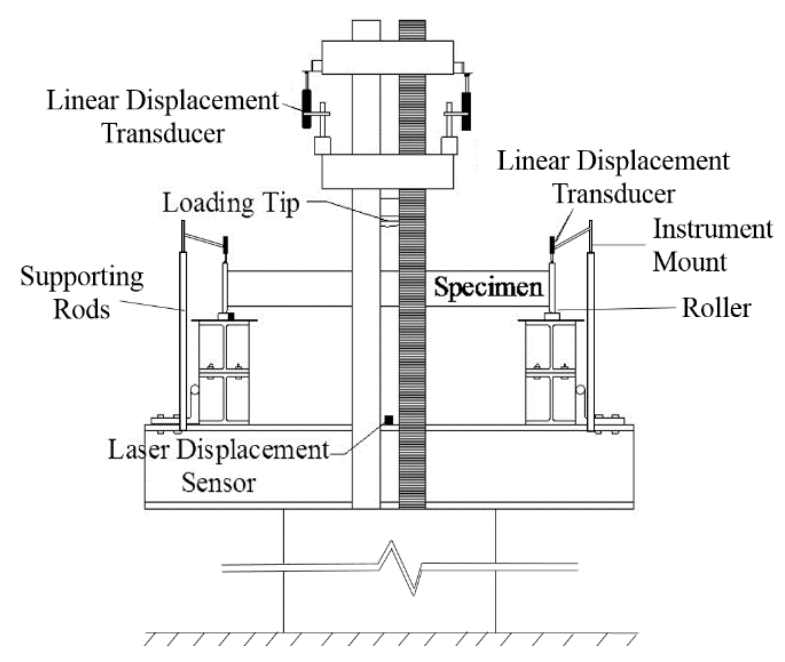

Fig. 2.Experimental Setup

\section{Finite Element Analysis}

The commercial finite element software, MSC Marc/ Mentat 2012 [15], has been implemented as the analytical tool. This software is a combination of MSC Marc and MSC Mentat. MSC Marc is nonlinear and linear analysis in the static and dynamic regimes. The nonlinearities may be due to concrete and steel behavior and large displacement.
MSC Mentat is used to prepare and process data for finite element analysis. It can generate the mesh, material and geometry assignment, loading conditions and boundary conditions. It used by MSC Marc to support the dedicated pre- and post-processor.

The iteration process is full Newton-Raphson iterative procedure. The residual checking and displacement checking value is set 0,1 , respectively. The iterative will be terminated when the convergence ratio is less than such values.

\subsection{Material Properties}

The steel stress-strain is the true stress and the equivalent plastic strain. The steel tube model is as shown in Fig. 3. The von Mises yield criterion and the kinematic hardening rule are used as the plastic flow conditions.

The infill concrete is simulated by Linear MohrCoulomb yield criterion combined with the isotropic hardening rule. The concrete model in compressive path is as shown in Fig. 4. The cracking concrete is specified to be a very small value of tensile stress and the tension softening modulus is specified to almost zero. The Poisson's ratio is assumed as 0.2 .

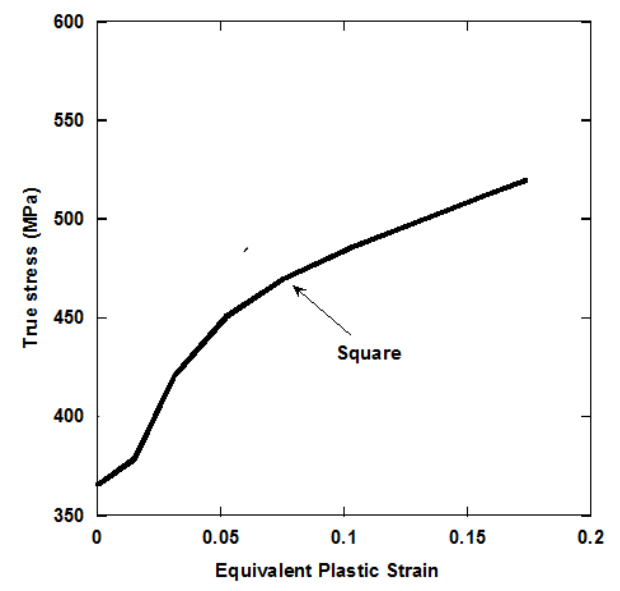

Fig. 3.Equivalent Plastic Strain and True Stress Relationships of Steel Tubes

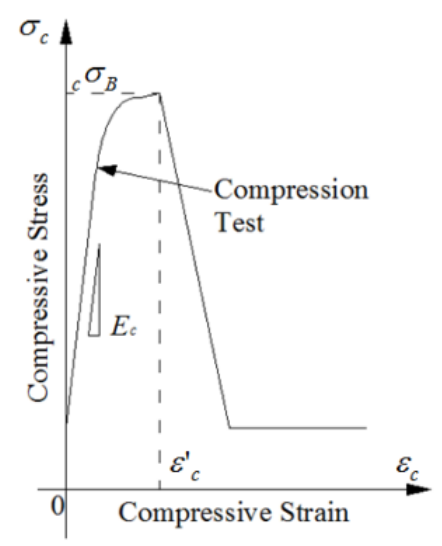

Fig. 4.Concrete Model in Compressive Path 


\subsection{Element Type, Boundary Conditions and Mesh Segmentation}

The eight-node solid element type 7 of MSC Marc with three degrees of freedom per a node $(u, v$ and $w)$ [19], is used for the analytical model of a steel tubular and concrete elements.

The beam with the pin-roller supports is subjected to concentrated load in the middle of the span. In both supports, all nodes are constrained in the direction of the $Y$-axis and one middle node is constrained to the $Z$ axis to stabilize the analysis. The remaining degree of freedom is set free. One node at the bottom of the beam in the mid-span is constrained to the $X$-axis.

Steel and concrete tubes were made by deformable elements. The loading tip is made of geometry and is controlled by displacement control. With respect to the end plate, shell elements are used with elastic material properties.

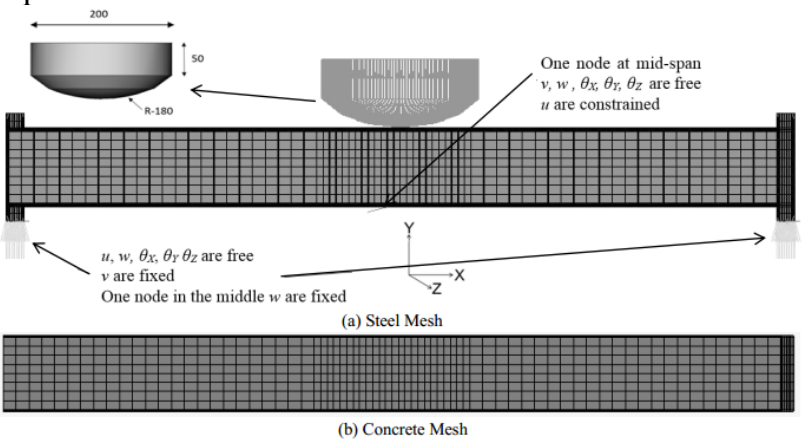

Fig. 5.Boundary Conditions and Mesh Segmentation with Contact Analysis

\subsection{Contact Analysis}

The geometry of the loading tip and a deformable element of steel tubular members are considered by means contact analysis. Such analysis also was implemented between deformable steel tubular elements and deformable concrete elements. The direct constraint procedure was implemented in the contact analysis [20].

\section{Fiber Element Analysis}

Nonlinear analysis computer program based on fiber element model can be performed for static and dynamic analysis, Kawano [16]. This program is implemented for nonlinear analysis of steel tubes filled with concrete loaded with static loads.

\subsection{Theory and method of analysis}

Assuming the plane in Fig. 6 (a) makes an element satisfies the following equation:

$$
\varepsilon=\varepsilon_{o}-y \kappa
$$

The section is divided into a several of layers which comprise of the stress fibers and the stiffness of cross sections is numerically integrated. The stress in the $j$ - $^{\text {th }}$ fiber is defined by elasto-plastic strain $\varepsilon_{e p}$ as follows:

$$
\sigma_{j}=\sigma_{j}\left(\varepsilon_{e p j}\right)
$$

Where, $\sigma_{j}$ is the $j^{- \text {th }}$ fiber stress, and $\sigma_{j}\left(\varepsilon_{e p j}\right)$ is stress-strain relation for $j-^{\text {th }}$ fiber in the section. With respect to $\varepsilon_{e p j}$, the $j$ - ${ }^{\text {th }}$ fiber elasto-plastic stress, due to that $\varepsilon$ incorporates three components (i.e. elasto-plastic strain $\varepsilon_{e p}$, creep strain $\varepsilon_{c r}$ and shrinkage strain $\varepsilon_{s h}$ ). The effects of shrinkage and creep are ignored, therefore, $\varepsilon$ only includes $\varepsilon_{e p}$ as follows:

$$
\varepsilon_{e p j}=\varepsilon_{o}-y_{j} \kappa
$$

The stress in all fibers are summed numerically to produce stress resultants as follows:

$$
S=\left[\begin{array}{l}
N \\
M
\end{array}\right]=\left[\begin{array}{c}
\sum_{j} A_{j} \sigma_{j} \\
-\sum_{j} A_{j} y_{j} \sigma_{j}
\end{array}\right]
$$

Where $N$ is the axial force, $M$ is the flexural moment, and $A_{j}$ is the area of the $j^{- \text {th }}$ fiber. $S$ is the generalized stresses vector. The assumption of the section stress is finally concentrated on centroid point as shown in Fig.6 (b).

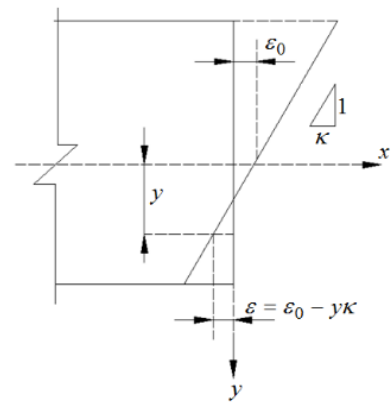

(a) Strain distribution

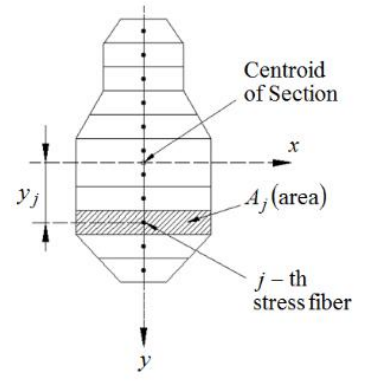

(b) Discretization of section
Fig. 6. Assumed Plane Section and Fiber Discretization of Section

An updated Lagrangean formula with the local coordinate axis moving together with elements in the global coordinate system, is used to calculate the effects of geometric nonlinearities. The three-point Gaussian integral evaluate the stiffness of the element.

\subsection{Fiber Discretization}

The lateral fiber discretization can be seen in Fig. 7 which is only horizontal orientation. The steel and concrete segments of CFT are divided into ten layers 
However, the top and bottom segment of steel tubular specimens, the horizontal fibers are subdivided into two layers. The stress fiber location is defined at each element centroid and to have the sectional area of the elements.

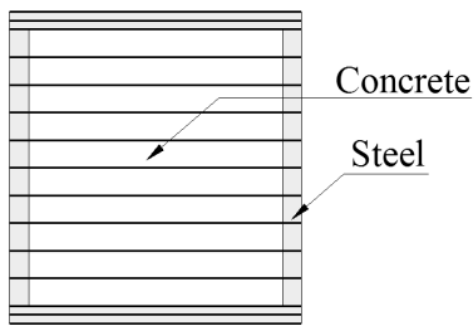

Fig. 7.Vertical Fiber Discretization

The longitudinal element discretization can be seen in Fig. 8. The plastic deformation may be thought to concentrate at the mid-span of the beam. The load is imposed by displacement control.

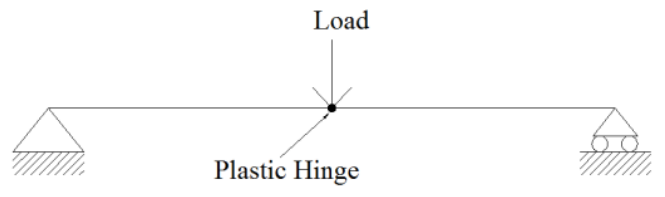

Fig. 8.Longitudinal Fiber Discretization

\subsection{Skeleton for stress-strain relation of concrete}

The skeleton curve for the concrete stress-strain is shown in Fig. 9. It consists of three branches, which are the ascending pre-peak curved line, the straight line for postpeak deterioration, and the glowing straight line for residual strength after completing deterioration. The two straight lines are to keep the simplicity with certain accuracy.

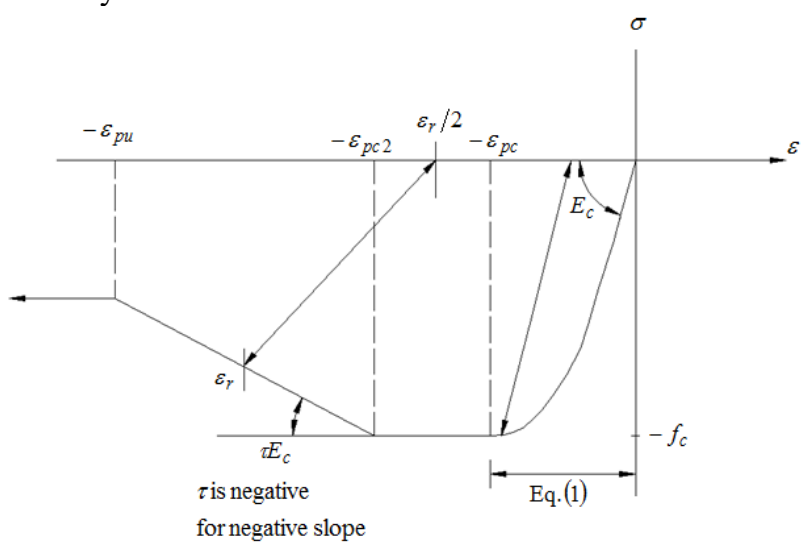

Fig. 9. Concrete Stress-strain Curve

$$
\begin{gathered}
\sigma=f_{c} \frac{r_{c}\left(\varepsilon / \varepsilon_{p c}\right)}{r_{c}-1+\left(\varepsilon / \varepsilon_{p c}\right)^{r_{c}}} \\
r_{c}=\frac{E_{c}}{E_{c}-E_{s c}}
\end{gathered}
$$

$$
E_{s c}=\frac{f_{c}}{\varepsilon_{p c}}
$$

$E_{c}=$ Young's modulus of concrete

$f_{c}=$ Maximum stress in compression

$\varepsilon_{p c}=$ Strain at the beginning of the maximum compression stress

$\varepsilon_{p c 2}=$ Strain at the end of the maximum compression stress

$\tau E_{c}=$ gradient of after peak stress

$\varepsilon_{p u}=$ strain limit

\subsection{Skeleton for stress-strain relation of steel}

With respect to the stress-strain model of steel tube components, the Menegotto-Pinto,denoted as M-P model [21], is used. The formula of M-P model is expressed by

$$
\frac{\sigma}{\sigma_{y}}=\frac{\left(1-\frac{E_{s, \infty}}{E_{s}}\right)\left(\frac{\varepsilon}{\varepsilon_{y}}\right)}{\left(1+\left[\frac{\varepsilon}{\varepsilon_{y}}\right]^{R}\right)^{\frac{1}{R}}+\left(1-\frac{E_{s, \infty}}{E_{s}}\right)\left(\frac{\varepsilon}{\varepsilon_{y}}\right)}
$$

$E_{s}=$ Steel Young's modulus

$E_{s, \infty}=$ Tangent modulus in the strain hardening range

$\sigma_{y}=$ Yield stress (stress at the intersection between skeleton curve and a line with stiffness of $E_{c} / 2$ which is almost the same as $0,2 \%$ offset value)

$R_{\text {ini }}=$ the $\mathrm{R}$ for the first M\&P curve of the skeleton curve, is assumed to have the values of 10

$\sigma_{u}=$ Maximum stress (stress at the strain 5\% in the second M\&P curve of the skeleton curve)

$R_{u}=$ the $R$ for the second M\&P curve of the skeleton curve, is assumed to have the values of 0.9

Fig. 10 shows the yield stress elongation and stress hardening after yield strength of steel component. It can be achieved based on Eq. 8 which is the combination of two M-P skeleton curves scaled by the yield strength ( $\left.\sigma_{y}\right)$ and ultimate strength $\left(\sigma_{u}\right)$, respectively.

\section{Theoretical Background}

The theoretical value of the ultimate moment, $M_{u}$, is based on the Recommendation by AIJ [22], where the stress distribution can be seen in Figure. 11. The ultimate axial forces, Eq. (9) equals zero by trial and error of $x_{n}$ value, so $M_{u}$, Eq. (10), can be calculated. The contribution of concrete and steel tubes in calculating the 
ultimate axial force is determined by Eq. (11) and Eq. (13), respectively. The contribution of concrete and steel

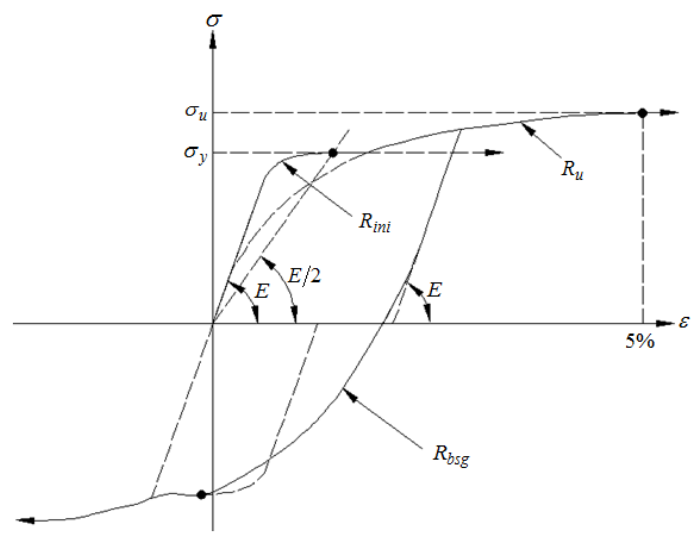

Fig. 10. Composition of Two M-P Curves in Skeleton

tubes at the ultimate moment is determined by Eq. (12) and Eq. (14), respectively.

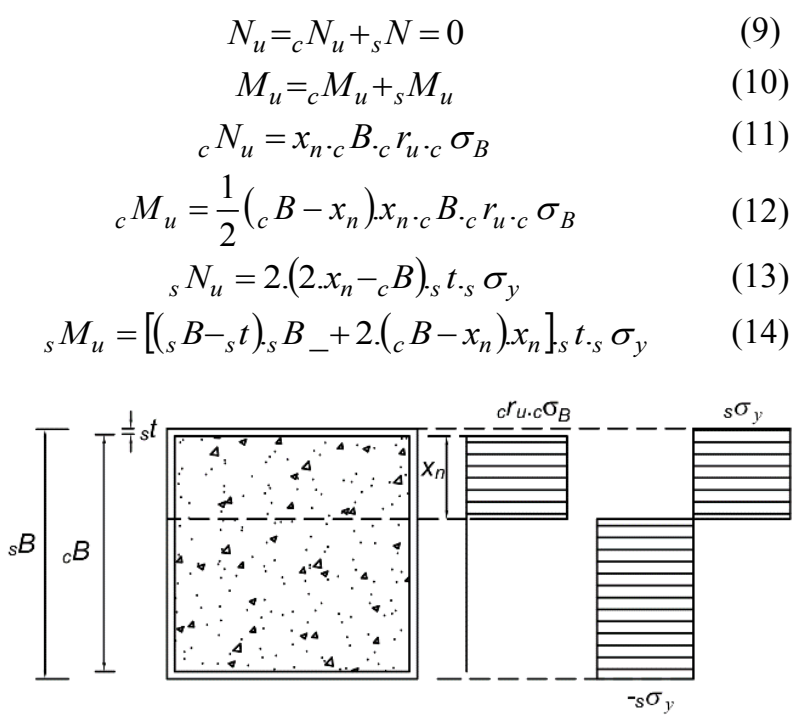

Fig. 11. Stress Block for CFST Members' Ultimate Bending Capacity

\section{Results and Discussions}

\subsection{Load-Deflection Relationships Comparison Among By Experiments, By Finite Element Analysis and By Fiber Element Analysis}

The load-deflection curve of the analysis of FEA and fiber element showed the shapes which are the same trend as with the result of the experiment. Each curve has an ascending path and reaches the maximum load value and then the load is constant. The ascending part is in linear and in inelastic manner. It is the initial stiffness is almost the same as the experiment. After the elastic behaviour of the specimen is exceeded, the plastic behaviour of FEM result showed lower than that of the experiment, while the fiber element result higher than that of the experiment. After the displacement reach about $35 \mathrm{~mm}$, the curve resulted from the analysis is the same as the experiment.

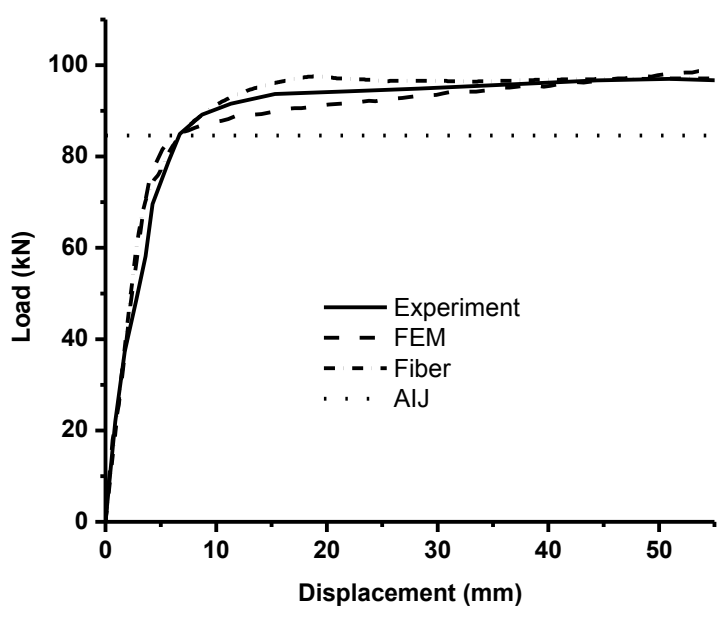

Fig. 12.Load-displacement Results Comparison of the Specimen

\subsection{Load-Strain Relationships Comparison Among By Experiments, By Finite Element Analysis and By Fiber Element Analysis}

The experimental strain data are taken from the strain gauge at the bottom of the midspan of the specimen. The yield strain is 0,0019 . After the yield strain is reached, as the load increased, the strain was basically increased nonlinearly (Fig. 13). The strain in the elastic range is almost the same. In the plastic range the strain showed the same trend.

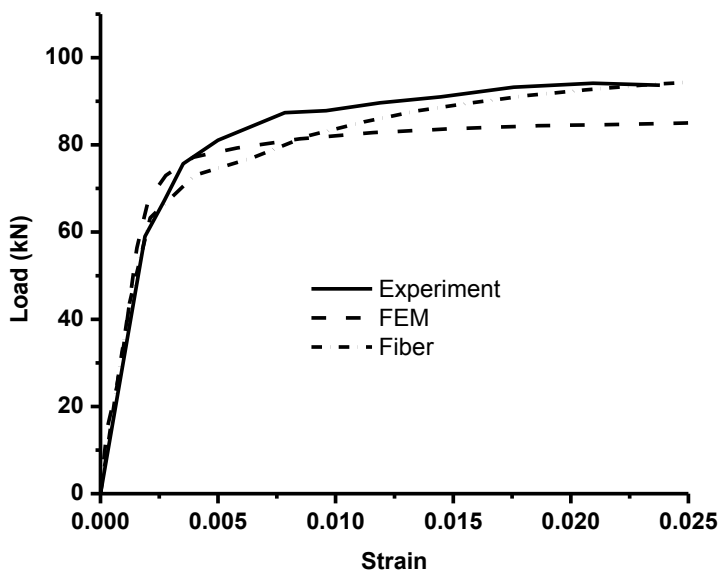

Fig. 13.Load-strain Results Comparison of the Specimen

\subsection{Axial Load Effect}

The fiber element analysis showed the results which are the same as the results of the experiment as shown in Fig. 12 and Fig. 13. The time duration of Fiber Element Analysis is shorter than that of FEM analysis. The ductility of the specimen degrade with the effect of [23]. The fiber element is used to study the effect of the axial load from the range $0 \% N_{u}$ to $40 \% N_{u}$. From Fig. 14, it 
can be seen that the $40 \% N_{u}$ degrade the ductility more than without axial load.

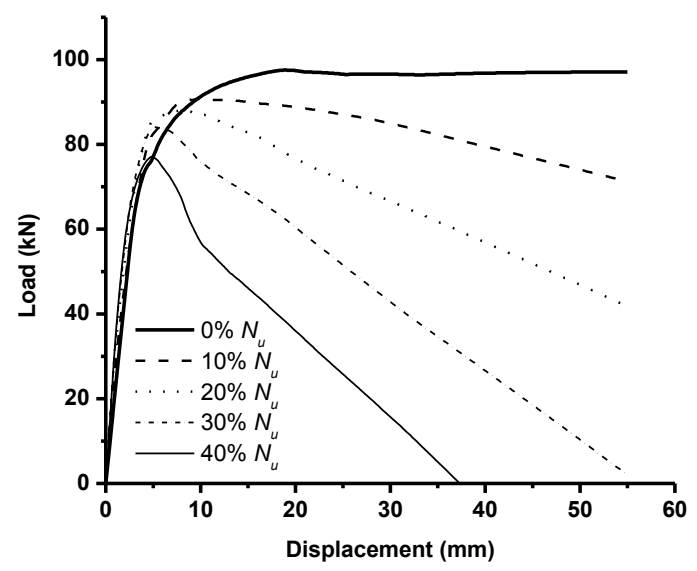

Fig. 14. The Axial Load effect on Load-displacement Relationship.

\section{Conclusion}

From the FEA and fiber element analysis of square steel tube beam with concrete infill, it can be concluded as follows:

1. The FEA model and fiber element analysis can model the experiment of the square steel tube beam with concrete infill accurately.

2. The results of load-deflection of the fiber element analysis and the full-scale FEA curves can be considered to coincide with the that of experimental results.

3. The results of load-strain of the fiber element analysis and the full-scale FEA curves can be considered to coincide with that of the experimental results in the elastic range. After the yield strain is extended, the curves showed the same trend as that of experimental results.

4. The axial load ratio effect is studied by means fiber element analysis. It shows that the axial load effect degrades the ductility of the CFT beam.

\section{Acknowledgment}

The authors are grateful to Prof. Akihiko Kawano of Department Architecture, Kyushu University for the research facility.

\section{References}

1. Y. Zhang, C. Xu, X. Lu, Experimental Study of Hysteretic Behaviour for Concrete-filled Square Thin-walled Steel Tubular Columns. Journal of Constructional Steel Research, 63(3), 317-325, (2007)

2. Y. C. Tang, L. J. Li, W. X. Feng, F. Liu, B. Liao. Seismic Performance of Recycled Aggregate
Concrete-filled Steel Tube Columns. Journal of Constructional Steel Research, 133, 112-124, (2017)

3. X. S.Shi, Q. Y.Wang, X. L. Zhao, F. G. Collins. Structural Behaviour of Geopolymeric Recycled Concrete-Filled Steel Tubular Columns under axial loading. Construction and Building Materials, 81, 187-197, (2015).

4. J. M. Cai, J. L. Pan, Y. F. Wu. Performance of Steelreinforced Square Concrete-filled Steel Hollow Section (SRSCFSHS) Columns under Uniaxial Compression. Advanced Steel Construction, 12(4), 410-427, (2016).

5. Y. F.An, L. H. Han, C. Roeder. Flexural Performance of Concrete-encased Concrete-filled Steel Tubes. Magazine of Concrete Research, 66(5), 249-267, (2014).

6. G. Li, D. Liu, Z. Yang, C. Zhang. Flexural Behavior of High Strength Concrete Filled High Strength Square Steel Tube. Journal of Constructional Steel Research, 128, 732-744, (2017).

7. C. C. Hou, L. H. Han, Q. L. Wang, C. Hou. Flexural behavior of circular concrete-filled steel tubes (CFST) under sustained load and chloride corrosion. Thin-Walled Structures, 107, 182-196, (2016).

8. M. Elchalakani, X. L. Zhao, R. Grzebieta. Concrete-filled Circular Steel Tubes Subjected to Pure Bending. Journal of Construction Steel Research, 57:1141-1168, (2000).

9. A. Karrech, M. Elchalakani, H. Basarir. Finite Element Modelling of Concrete Filled Steel Tubes Subjected to Static Pure Bending. In H. Hao, \& C. Zhang (Eds.),Mechanics of Structures and Materials XXIV: Proceedings of the 24th Australian Conference on the Mechanics of Structures and Materials (Vol. 1, pp. 143-148). London, (2017).

10. F. K. Idan. Finite Element Analysis of Concretefilled Aluminum tube columns. International Journal of Applied Engineering Research, 12(12), 3054-3062, (2017).

11. S. Arivalagan, S. Kandasamy. Finite element analysis on the flexural behaviour of concrete filled steel tube beams. Journal of Theoretical and Applied Mechanics, 48(2), 505-516, (2010).

12. Z. Ting, C. Zhihua, L. Hongbo. Nonlinear finite element analysis of concrete-filled steel tubular column. In Electric Technology and Civil Engineering (ICETCE), 2011 International Conference on (pp. 2396-2399). IEEE, (2011).

13. P. K. Gupta, H. Singh. Numerical study of confinement in short concrete-filled steel tube columns. Latin American Journal of Solids and Structures, 11(8), 1445-1462, (2014).

14. M. H. Mollazadeh, , \& Wang, Y. C. (2014). New insights into the mechanism of load introduction into concrete-filled steel tubular column through shear connection. Engineering Structures, 75, 139151. 
15. MSC. MARC. User's Guide, MSC. Software Corporation, (2012).

16. A. Kawano, R.F. Warner. Nonlinear Analysis of the Time-Dependent Behaviour of Reinforced Concrete Frames, Research Report No. R125, Department of Civil and Environmental Engineering, the University of Adelaide, (1995)

17. Y. Bai, X. Lin, B. Mou. Numerical modeling on post-local buckling behavior of circular and square concrete-filled steel tubular beam columns. International Journal of Steel Structures, 16(2), 531-546, (2016).

18. M. K. Effendi, A. Kawano. A study on the static and impact structural behavior of concrete filled steel tubular members under Tsunami flotsam collision. In AIP Conference Proceedings (Vol. 1818, No. 1, p. 020011). AIP Publishing, (2017).

19. MSC. MARC. Marc 2012 Volume B, MSC. Software Corporation, (2012).

20. MSC. MARC. Marc 2012 Volume A, MSC. Software Corporation, (2012).

21. M. Menegotto, P. E. Pinto, Method of Analysis for Cyclically Loaded R. C. Frames Including Changes in Geometry and Non-elastic Behaviour of Elements under Combined Normal Force and Bending, IABSE Congress Reports of the Working Commission, Band 13, (1973).

22. Architectural Institute of Japan (AIJ). Recommendations for design and construction of concrete-filled steel tubular structures, (2008). (in Japanese)

23. F. Alhussainy, M. N. Sheikh, M. N. Hadi. Behaviour of Small Diameter Steel Tubes Under Axial Compression. In Structures, Vol. 11, pp. 155-163, (2017). 